\title{
Rasionalitas dan Aktualitas Kearifan Lokal Sebagai Basis Pendidikan Karakter
}

\author{
Al Musanna \\ Sekolah Tinggi Agama Islam Gajah Putih Takengon, Aceh Tengah \\ (win_moes@yahoo.co.id/winmoes78@gmail.com)
}

\begin{abstract}
Abstrak: Indonesia adalah negara yang kaya dan unik. Demikian ungkapan para peneliti dan wisatawan setelah berkunjung dan menjelajahi negeri yang terdiri dari ratusan etnis dan tersebar di ribuan pulau ini. Sangat mudah menemukan betapa uniknya bangsa ini, ditinjau dari bahasa, kesenian, pola hidup, kearifan lokal, dan lain-lain. Khazanah keragaman yang luar biasa tersebut merupakan modal lebih dari cukup untuk mengembangkan corak atau model pendidikan yang berakar pada kearifan lokal yang tersebar di seluruh wilayah Indonesia. Ketika pemerintah mendengungkan pendidikan karakter, penggalian kembali nilai-nilai kebajikan dan kearifan lokal merupakan harta terpendam yang menunggu sentuhan tangan dingin untuk diaktualisasikan. Kearifan lokal dalam setiap komunitas merupakan pencerminan dari falsafah hidup terintegrasi (holistik) yang dalam pusaran sejarahnya berhasil mewujudkan harmoni manusia dengan sesama dan lingkungan. Memang terkesan terlambat kesadaran mengenai pendidikan karakter, tetapi bukankah terlambat masih lebih baik daripada tidak sama sekali.
\end{abstract}

Kata Kunci: kearifan, kearifan lokal, pendidikan karakter, suku gayo

\begin{abstract}
Indonesia is a rich and unique country. It's easy to find how unique this nation in terms of language, art, lifestyle, local wisdom, and others. No need to go far from the state capital to find the articulation of cultural diversity. The extraordinary diversity is more than enough to be used to develop a pattern or model of education that is rooted in the local wisdom scattered throughout the territory of Indonesia. When the character education is trenching returned values of virtue and wisdom can be one of the alternatives. Local wisdom in every community is a reflection of the philosophy of life (world-view), an integrated vision that is existed in historical period which has succeeded in realizing harmony of human beings and the environment. It seemed too late awareness of character education, but late is still better than nothing.
\end{abstract}

Key words: wisdom, local wisdom, character education, gayo ethnic.

\begin{abstract}
Pendahuluan
Dalam beberapa waktu terakhir, muncul antusiasme untuk mengartikulasikan kearifan lokal sebagai pijakan dalam memperkaya praksis pendidikan. Gerakan ini dilatarbelakangi keyakinan bahwa modernitas dengan segala perangkat pendukungnya tidak cukup memadai meghantarkan manusia dalam menjalani kehidupan yang lebih bermakna dan mencapai kebahagiaan yang autentik (authentic happiness). Modernitas dengan rasionalitas, objektifitas, dan kebebasan individu yang tercerabut dari akar spiritualitas dan kearifan telah membawa dampak terjadinya ketidakseimbangan (disekualibrum) hubungan manusia, baik dengan sesamanya maupun dalam interaksinya dengan alam.
\end{abstract}

Gagasan pengembangan pendidikan berbasis kearifan lokal (local wisdom-based education) berpijak pada keyakinan bahwa setiap komunitas mempunyai strategi dan teknik tertentu yang dikembangkan untuk menjalankan kehidupan sesuai konteksnya. Pendidikan berbasis nilai diperlukan untuk mengembangkan kualitas moral, kepribadian, sikap kebersamaan yang semakin tergerus oleh perkembangan zaman (Aspin \& Chapman, Ed., 2007). Dalam dunia pendidikan formal, penekanan berlebihan pada pengembangan sisi kognitif peserta didik berdampak pada tidak proporsionalnya waktu, perhatian dan dukungan terhadap pengembangan dimensi afektif peserta didik. Pemerhati dan penulis sejumlah literatur pendidikan mengungkapkan, 
"...traditionally, the focus of schools has been cognitive. Students and teacher are rewarded for academic gains, not affective or humanistic progress" (Lang dan Evan, 2006).

Menyadari kompleksitas pengintegrasian kearifan lokal sebagai basis pendidikan karakter, tulisan ini akan mendiskusikan tiga hal: polemik mengenai apakah kearifan dapat diajarkan; relevansi kearifan lokal sebagai landasan pendidikan karakter dengan mengacu pada teori pengajaran kearifan (teaching for wisdom); dan aktualisasi teaching for wisdom sebagai landasan pengembangan model integrasi kearifan lokal sebagai basis pendidikan karakter.

\section{Kajian Literatur dan Pembahasan}

\section{Pengertian Kearifan, Kearifan Lokal dan Pendidikan Karakter}

Tesaurus Indonesia menempatkan kata kearifan sejajar dengan kebajikan, kebijakan, kebijaksanaan dan kecendekiaan. Sedang kata arif memiliki kesetaraan makna dengan: akil, bajik, bakir, bestari, bijak, bijaksana, cendekia, cerdas, cerdik, cergas, mahardika, pandai, pintar, dan terpelajar (Sugono, dkk, Ed., 2008). Dalam tradisi kesarjanaan Islam, istilah arif (hikmah) dan ilmu ('ilm) sering diidentikkan dan terkadang diposisikan yang satu sebagai subordinat lainnya. Berdasar penelusuran Rosenthal (2007) istilah hikmah secara substansial merujuk pada level atau tingkat kesadaran tertinggi yang berada di atas pengetahuan, "'wisdom' is something better than 'knowledge.' It embodies a higher degree of knowledge and insight in the realm of both human perceptions and theological speculation." Sternberg (2003) Sternberg dalam Preiss dan Sternberg, Ed., (2010) Sternberg dalam Kaufman dan Grigorenko, Ed., (2009) mengartikan kearifan (wisdom) sebagai pemanfaatan secara terpadu kecerdasan, kreativitas dan pengetahuan yang diperantarai seperangkat nilai dalam pencapaian kebaikan bersama (common good) melalui pertimbangan yang seimbang antara kepentingan intrapersonal, interpersonal dan ekstrapersonal yang berlangsung dalam jangka waktu singkat atau lama untuk beradaptasi, membentuk atau memilih lingkungan.

Kearifan lokal merupakan akumulasi dari pengetahuan dan kebijakan yang tumbuh dan berkembang dalam sebuah komunitas yang merepresentasikan perspektif teologis, kosmologis dan sosiologisnya. Terdapat beberapa istilah yang digunakan secara bergantian dalam memaknai kearifan lokal (Ingg. local wisdom), misalnya pengetahuan lokal (local knowledge); budaya lokal (local culture); keunggulan lokal (local genius); budaya pribumi (indigenous culture); dan pengetahuan asli (indigenous knowledge). Di Indonesia istilah kearifan lokal akhir-akhir ini lebih populer digunakan dibanding istilah-istilah lainnya, hal ini sebagaimana tercermin pada penggunaan istilah ini dalam literatur, media massa, dan percakapan sehari-hari. Abubakar (2010) mengartikan kearifan lokal sebagai kebijakan yang bersandar pada filosofi, nilai-nilai, etika, dan perilaku yang melembaga secara tradisional untuk mengelola sumber daya (alam, manusia, dan budaya) secara berkelanjutan. Kearifan lokal sebagai kebenaran yang mentradisi atau ajeg merupakan perpaduan nilai-nilai suci firman Tuhan dan nilai turun-temurun yang dikembangkan komunitas tertentu. Sesorang dinilai arif apabila dapat mengakumulasi dan mengkolaborasikan antara konteks dan nilai-nilai yang melingkupinya, serta dapat mewujudkan pola hidup yang seimbang, tidak mungkin seseorang dipandang bijak apabila sikap dan tindakannya berlawanan dengan nilai yang berlaku (Sternberg dalam Shavinina dan Ferrari, Ed., 2004).

Istilah karakter berasal dari bahasa Yunani yang bermakna, "instrument for marking and graving, impress, stamp, distinctive mark, distinctive nature' (Kupperman, 1990: 3). Karakter berkaitan dengan ciri atau tanda khusus yang melekat pada suatu benda atau seseorang. Seseorang yang berkarakter (baik atau buruk) membuatnya tampil beda dari orang lain, sehingga menjadi penanda khusus ketika orang lain mengenalinya (Dimenson, 2009). Wilhelm (2005), setelah melakukan tinjauan terhadap sejumlah definisi yang diajukan para pakar menyatakan, "character can be measured corresponding to the individual's observance of a behavioral standard or the individual's compliance to a set moral code. "Dengan demikian, karakter merupakan representasi identitas seseorang yang menunjukkan ketundukannya pada aturan atau standar moral yang 
berlaku dan merefleksikan pikiran, perasaan dan sikap batinnya yang termanifestasi dalam kebiasaan berbicara, bersikap dan bertindak.

Pendidikan karakter meskipun populer digunakan tetapi upaya merumuskan definisi yang disepakati ternyata tidak mudah (Peterson \& Seligman, Ed., 2004; Nuccy \& Narvaez, Ed., 2008). Creasy (2008) menyatakan, "...character education is a program that can be implemented in order to turn students into respectful, responsible, contributing members of society." Pendidikan karakter dapat dimaknai sebagai upaya men dorong peserta didik tumbuh dan berkembang dengan kompetensi berfikir dan berpegang teguh pada prinsip-prinsip moral serta mempunyai keberanian melakukan yang benar, meskipun dihadapkan pada berbagai tantangan. Pendidikan karakter tidak terbatas pada transfer pengetahuan mengenai nilai-nilai yang baik ansich, tetapi menjangkau bagaimana menjadikan nilai-nilai tersebut tertanam dan menyatu dalam totalitas pikiran-tindakan (Dimenson, Ed., 2009). Lickona (1991) dalam Education for Character: How Our School Can Teach Respect and Responsibilty menyebutkan bahwa pembentukan karakter meliputi tiga hal berikut: mengetahui yang baik (knowing the good), kemauan melakukan kebaikan (desiring the good) dan melakukan tindakan yang baik (doing the good).

\section{Rasionalitas Kearifan Lokal sebagai Basis Pendidikan Karakter}

Pembahasan pendidikan karakter tidak mungkin dapat dipisahkan dari nilai-nilai yang melekat pada konteks. Kearifan lokal merupakan representasi dari pandangan hidup (wolrd view/way of life) yang tumbuh dan berkembang dalam sebuah komunitas. Dalam masyarakat yang didominasi peradaban olah-pikir, contohnya zaman keemasan Athena tempoe doeloe, karakter yang sangat diidamkan adalah tercermin pada orang-orang yang menyandang gelar filosuf. Berbanding terbalik dengan kondisi tersebut, dalam tradisi masyarakat yang didominasi olah-pisik, sebagaimana berkembang dikalangan penduduk Sparta, derajat seseorang ditentukan kebugaran dan kekuatan pisiknya. Karakter terhormat ditempati olahragawan sekelas Achilles, Hercules, dan lainlain.
Kearifan perlu dikembangkan menjadi bagian integral kurikulum pendidikan pada semua jenis dan jenjangnya. Lembaga pendidikan moderen telah menyingkirkan kearifan dari sekolah dan membatasi prioritasnya pada peningkatan kecerdasan peserta didik yang diukur pada kemampuan menghapal materi dan keterampilan melakukan tugas-tugas. Sternberg, Jarvin dan Reznitskaya (dalam Ferrari dan Potrowowski, Ed., 2008) mengungkap kegelisahannya terhadap praksis pendidikan moderen yang mengabaikan atau memberi perhatian sangat sedikit untuk mempersiapkan peserta didik menjadi pemikir dan manusia yang arif, hal ini sebagaimana dinyatakannya berikut ini, "Western education in the past of couple of centuries has typically focused on imparting content knowledge and developing cognitive skills in students. Schools promote intelligent-but not necessarily wise students." Dengan kenyataan tersebut, meskipun secara akademis peserta didik memperoleh nilai tinggi, tetapi mereka gagal memperlakukan kehidupan dengan baik, sehingga sering melakukan tindakan tidak bijak (foolishness) yang merugikan dirinya sendiri dan orang lain (Sternberg dalam Sternberg dan Jordan, Ed., 2005).

Pertanyaan mengenai mungkinkah kearifan diajarkan telah mendapat respon yang beragam. Mulai dari kalangan yang menyatakan ketidakmungkinannya, kelompok yang ragu-ragu dan yang yakin bahwa kearifan meskipun tidak sepenuhnya dapat diajar tetapi dapat dikembangkan. Sejumlah peneliti mengemukakan bahwa benar kearifan tidak dapat ditransfer, tetapi melalui pemodelan dan ketersediaan lingkungan yang kondusif, kearifan dapat dikembangkan sebagai karakter peserta didik. Dalam Teaching for Wisdom Through History: Infusing Wise Thinking Skills in the School Curriculum, Sternberg, Jarvin dan Reznitskaya (dalam Ferrari dan Potworowski, Ed., 2009) menyatakan bahwa sekolah dapat membantu mengembangkan kearifan. Konsepsikonsepsi kearifan lokal yang diwariskan secara turun temurun melalui dongeng, legenda, petuahpetuah adat merupakan strategi transformasi nilai-nilai yang dipandang penting untuk dimiliki anak. Pendidikan dalam maknanya yang luas mencakup pedoman menjalankan kehidupan dengan bijaksana, sehingga tidak mencederai 
derajat kemulian manusia sebagai pemegang amanah mengelola sumber daya alam yang dianugerahkan Tuhan (Reagen, 2005).

\section{Teori Teaching for Wisdom}

Dalam rentang perjalanan sejarah manusia, berbagai cara dilakukan untuk menjadi orang yang arif atau bijak. Berbagai kajian baik melalui filsafat, antropologi dan akhir-akhir ini berbagai aliran psikologi alternatif juga mulai mengkaji kearifan (Kresse dalam Ferrari dan Potworowski, Ed., 2008). Dalam A Handbook of Wisdom, Sternberg dan Jordan, Ed., (2005) melakukan pembahasan yang menarik mengenai berbagai pendekatan dalam mengkaji kearifan. Dari sudut pandang psikologi, ketertarikan para psikolog didorong ketidakmemadaian psikologi konvensional menjelaskan kompleksitas manusia, hal ini sebagaimana dikemukakan Sternberg (dalam Shavinina dan Ferrari, Ed., 2004) bahwa pengukuran kecerdasan sebagaimana terdapat pada tes intelligensi tidak mampu menjelaskan secara memuaskan mengenai hakikat kearifan.

Teori pengajaran kearifan (teaching for wisdom) merupakan pengembangan teori keseimbangan kearifan (Balance Theory of Wisdom) yang diperkenalkan sejak penghujung tahun 90-an (Sternberg, 2003; Sternberg dalam Kaufman dan Grigorenko, Ed., 2009). Melalui program pengajaran untuk kearifan menunjukkan terdapat korelasi dan peningkatan kearifan peserta didik setelah diaplikasikannya model kurikulum yang mengintegrasikan prinsip dan prosedur pengajaran kearifan (Sternberg, 2010 Sternberg dalam Preiss dan Sternberg, Ed., 2010; Sternberg dalam Staudinger dan Gluck dalam Sternberg dan Kaufman, Ed., 2011).

Pengajaran kearifan terdiri dari 16 prinsip, demikian dikemukakan Sternberg (2003) dalam Wisdom, Intelligence, and Creativity Synthesized. Berikut adalah prinsip-prinsip paedagogis pengajaran kearifan: guru memberi ruang kepada peserta didik untuk mengeksplorasi bahwa prestasi dan capaian akademis tidak memadai menjawab kompleksitas modernitas; menunjukkan kepada peserta didik bahwa kearifan merupakan bagian penting mewujudkan kehidupan yang bahagia; mengajak peserta didik mengembangkan pola berpikir interdependensi; guru menjadi teladan dalam mempraktikkan sikap yang arif (rolemodel); menyediakan literatur tentang kearifan; menekankan pentingnya sarana pencapaian tujuan, tidak menjadikan tujuan sebagai akhir segalanya; memotivasi peserta didik berfikir dialektis, dialogis, kritis, dan kreatif; membiasakan peserta didik melakukan penyesuaian (adaptation), membentuk (shaping), dan memilih (selection) lingkungan yang dapat membantu meningkatkan kearifan dirinya; memberi semangat dan hadiah dalam mendorong konsistensi peserta didik dalam meningkatkan kearifan.

Berdasarkan prinsip-prinsip tersebut, Sternberg (2003; Sternberg, Jarvin dan Reznitskaya dalam Ferrari dan Potworowski, Ed., 2009) merumuskan enam prosedur pengajaran kearifan. Keenam tahapan pembelajarannya meliputi: "First, student would read classic works of literature and philosophy to learn and reflect on the wisdom of sages; Second, student would engage in class discussions, projects, and essays that encourage them to discuss the lesson they have learned from classic works, and how they can applied to their own lives and the lives of other; Third, students would study not only truth, as we know it, but values as well; Fourth, instruction would place an increased emphasis on critical, creative and practical thinking in service of good ends; Fifth, students would be encouraged to think about how almost everything they study might be used fot better or worse end; Finally, teachers serve as role models." Secara sederhana, enam prosedur yang dikemukakan tersebut melalui orkestrasi tiga komponen berikut: Pertama, integrasi pendekatan pembelajaran kecakapan berfikir arif (wise thinking skills); Kedua, penciptaan iklim pembelajaran yang mendorong kebiasaan berfikir dan bertindak arif; dan Ketiga, komitmen guru sebagai teladan (rolemode/) membiasakan prilaku arif. Terkait komponen terakhir, Sternberg, Jarvin dan Reznitskaya (dalam Ferrari dan Potworowski, Ed., 2009) menyatakan, "the most effective teacher is likely to be one who can create a classroom community in wich wisdom is practiced, rather than preached." 
Aktualitas Teaching for Wisdom: Studi Kearifan Lokal Masyarakat Gayo sebagai Basis Pendidikan Karakter

\section{Gambaran Singkat Etnis Gayo}

Masyarakat Gayo adalah salah satu suku asli yang mendiami provinsi Aceh, khususnya berada di dataran tinggi Gayo (Kabupaten Aceh Tengah, Bener Meriah dan Gayo Lues dan Aceh Tenggara) dan menempati posisi kedua sebagai suku asli terbesar di Aceh. Berdasar perkiraan bahasa Gayo digunakan sekitar 260.000 orang (Eides, 2005; Eades dan Hajek, 2006). Dalam Grammar of Gayo: A Language of Aceh Sumatera dikemukakan bahwa bahasa Gayo termasuk keluarga bahasa Austronesia (Nias, Mentawai, Enggano, dan Batak) dan sebagian besar kosa katanya atau sekitar 40 persen secara leksikal berasal dari bahasa Melayu (Eades, 2005; Melalatoa, 1982).

Masyarakat Gayo (orang setempat menamakan dirinya urang Gayo) mempunyai hubungan genealogis dengan orang Melayu Tua. Dalam Aceh Sepanjang Abad, Said (1985) mengemukakan bahwa nenek moyang orang Gayo berasal dari Melayu Tua yang menyingkir dari pesisir pantai ke pedalaman disebabkan kedatangan Melayu Muda dari Indo-Cina dan Kamboja pada tahun 300 SM. Mereka menetap di sepanjang pantai utara dan timur Aceh dan di sepanjang aliran sungai Jambo Aye, Peureulak, dan Kuala Simpang. Seorang pemakalah Seminar Temu Budaya Nusantara pada Pekan Kebudayaan Aceh Ke-3 Tahun 1988 mengemukakan, "...sebelum orang Aceh yang berasal dari Campa tiba di Aceh, kawasan ini didiami suku-suku lain dari Austronesia, misalnya orang Gayo, di samping bangsa Mantir (Mente) yang tergolong dalam rumpun Mon Khmer" (Ibrahim, 2007). Hikayat Raja-Raja Pasai (ditulis tahun 1814 M.) merupakan literatur tertua yang mendeskripsikan pola hidup sekelompok orang yang mendiami dataran tinggi ini (diyakini sebagai leluhur suku Gayo) dan telah mengembangkan pola bercocok tanam untuk memenuhi kebutuhan hidupnya (Bowen, 1993).

Berdasar narasi yang berkembang luas di kalangan masyarakat Gayo (kekeberen), kerajaan pertama dikawasan tersebut didirikan Genali yang datang dari Rum (Turki) sekitar abad X Masehi (Melalatoa, 1982; Gayatri, 2008). Menurut versi ini, Raja Linge sudah berhubungan dengan raja
Johor melalui pengiriman hadiah dan utusan, bahkan raja Linge menikahi putri raja Johor. Rombongan pengiring putri kerajaan Johor yang terdiri dari 30 orang, akhirnya tinggal di Gayo dan diberi gelar Cik, Kejurun, Reje dan Penghulu. Dengan bertambahnya penduduk, kerajaan Linge dipecah menjadi kerajaan-kerajaan kecil, yaitu kerajaan Bukit di sekitar Danau Laut Tawar, kerajaan Serule, kerajaan Syiah Utama, bahkan meluas hingga daerah Batak Karo di Sumatera Utara dengan kerajaan Sibayak Lingga, dan di Sumatera Barat dengan kerajaan Wi Apuk dan Bedagai (Gayatri, Ed., 2008). Setelah berdirinya kerajaan Islam Pereulak dan terjadinya serbuan kerajaan Sriwijaya pada tahun 986 M, adik Sultan Peureulak yang bernama Malik Ishak bersama pelarian politik lainnya yang berjumlah sekitar 300 orang menetap dan diberi hak mendirikan kerajaan Islam di Isaq (45 Kilometer dari ibukota Aceh Tengah yang sekarang), yang kemudian bernama Kerajaan Malik Ishaq (Syukri, 2007; Ibrahim, 2003).

Kajian mengenai eksistensi masyarakat Gayo telah dimulai sejak awal abad ke-20 oleh kolonial Belanda sebagai bagian dari strategi militer melumpuhkan perjuangan rakyat Aceh. Orientalis kenamaan dan sekaligus penasehat kebijakan politik Belanda, C. S. Hourgrounje dipandang sebagai peletak kajian mengenai suku Gayo (Melalatoa, 1982). Tulisan Hourgrounje mengenai masyarakat Gayo dipublikasikan pertama kali tahun 1906 berjudul Het Gayoland en Zijne Bewoners, yang telah dialih-bahasakan menjadi Tanoh Gayo dan Penduduknya (1996). Peneliti lain mengenai masyarakat Gayo di Kabupaten Aceh Tengah juga dilakukan Bowen (1984; 1993; 2003), yang dimulai dari studi penyelesaian disertasi antropologinya di Universitas Chicago pada penghujung 70-an dan berlanjut sampai awal tahun 80-an. Pada tahun 70-an, Melalatoa (mahasiswa antropologi Universitas Indonesia dan setelah menyelesaikan studinya diangkat sebagai dosen dan guru besar etnologi di almamaternya) terlibat dalam penelitian dan pendokumentasian kebudayaan Gayo yang dibiayai Departemen Pendidikan dan Kebudayaan, yang mempublikasikan temuannya dalam sejumlah buku, di antaranya: Kamus Bahasa Gayo-Indonesia (1966); Kesenian Didong dan 
Perubahan Masyarakat di Gayo (1971); Sastra Lisan Masyarakat Gayo (1980); Kebudayaan Gayo (1982); dan disertasi Pseudo-Moiety Gayo: Satu Analisa tentang Hubungan Sosial Menurut Kebudayaan Gayo (1983). Karya-karya Melalatoa memberi kontribusi penting memotivasi kajian lebih spesifik mengenai berbagai dimensi budaya Gayo pada masa-masa selanjutnya.

Dikalangan masyarakat Gayo sendiri, terdapat beberapa penulis yang karyanya dikenal luas, diantaranya adalah A.R. Hakim Aman Pinan dan Drs. H. Mahmud Ibrahim. Aman Pinan dikenal sebagai tokoh adat Gayo dan dipercaya sebagai ketua Lembaga Adat dan Kebudayaan Aceh (LAKA) Kabupaten Aceh Tengah sejak tahun 1991 sampai meninggalnya tahun 2004. Di antara karya yang telah dihasilkan Aman Pinan adalah: Daur Hidup Gayo (1998); Hakikat Nilai Budaya Gayo (1998); 1001 Pepatah-Petitih Gayo (1993); Asal Linge Awal Serule (2002). Bersama Mahmud Ibrahim, Aman Pinan merampungkan seri buku mengenai Syariat dan Adat Istiadat Gayo sebanyak tiga jilid (Ibrahim dan Pinan, 2002; 2005; 2010). Sejumlah penelitian dalam bentuk skripsi, tesis, dan disertasi juga dalam beberapa tahun terakhir mulai menunjuk-kan perhatian mengenai aspek-aspek kearifan masyarakat setempat, meskipun lebih banyak lagi aspek kearifan yang belum terungkap dan sebahagian diantaranya hilang tergerus perkembangan zaman.

\section{Kearifan Lokal masyarakat Gayo}

Sebagai entitas sosial yang dinamis, masyarakat Gayo mengkonstruksi kearifan lokal sebagai pandangan-dunia memaknai realitas (Bowen, 1991). Kearifan lokal yang merupakan representasi budaya sebuah komunitas diartikulasikan baik dalam wujud kasat mata (tangible) maupun yang tidak kasat mata (intangible). Dalam klasifikasi sejumlah pakar, terdapat lima kategori kearifan lokal: pertama, kearifan yang berupa pandangan hidup (filosofi); kedua kearifan berupa sikap hidup sosial, nasihat dan iktibar yang diungkap dalam bentuk pepatah, perumpamaan, pantun syair atau cerita rakyat (folklor); ketiga, kearifan dalam seremoni atau upacara adat; keempat, kearifan berupa prinsip, norma, dan tata aturan yang berwujud menjadi sistem sosial; dan kelima, kearifan berupa kebiasaan, prilaku sehari-hari dalam pergaulan sosial (Rasyidin, Siregar dan Batubara, dalam Afif, Bahri dan Saeful, Ed., 2009).

Dalam konteks masyarakat Gayo, kearifan lokalnya terangkum dalam konsep "ed"et atau adat, yang meliputi praktik, norma, dan tuntutan kehidupan sosial yang bersumber dari pengalaman yang telah melalui islamisasi (Bowen, 2003). Wujud kearifan lokal yang terdapat dalam masyarakat Gayo meliputi bahasa Gayo, sistem tata kelola pemerintahan (sarakopat), norma bermasyarakat (sumang), ekspresi estetik (didong), konsep nilai dasar budaya Gayo, dan lainlain (Ibrahim dan Pinan, 2010; Melalatoa, 1982). Dimensi kearifan lokal dalam masyarakat Gayo terangkum dalam nilai dasar budaya yang merepresentasikan filosofi, pandangan hidup dan karakter ideal yang hendak di capai. Merujuk klasifikasi Melalatoa terdapat tujuh nilai budaya Gayo, dimana terdapat satu nilai puncak yang merupakan representasi kearifan lokal yang berbasis nilai-nilai Islami. Untuk memberi gambaran mengenai sistem nilai budaya Gayo, Melalatoa (1982) mendeskripsikan pada skema 1 berikut:

Sistem nilai budaya Gayo menempatkan harga diri (mukemel) sebagai nilai utama. Untuk mencapai tingkat harga diri tersebut, seseorang harus mengamalkan atau mengacu pada sejumlah nilai penunjang: tertip, setie, semayanggemasih, mutentu, amanah, genap-mupakat, alangtulung. Untuk mewujudkan ke-tujuh nilai penunjang perlu nilai penggerak, bersikekemelen. Berikut dikemukakan penjelasan singkat mengenai sistem nilai ini.

\section{Mukemel}

Konsep mukemel berkenaan dengan harga diri. Istiah kemel pada dasarnya berarti malu. Dalam aplikasinya malu dipahami dalam makna yang lebih luas, sehingga mencakup makna harga diri atau iffah dalam konsep studi akhlak. Konsep ini merujuk pada kemampuan menjaga diri agar tidak terjerumus pada pikiran dan tindakan yang dapat menyebabkan hilangnya harga diri. Seorang yang mempunyai sikap mukemel konsisten mempertahankan harga diri dengan mencegah diri atau keluarganya terjebak pada perbuatan-perbuatan tercela atau bertentangan dengan tuntunan agama (syariat) dan norma kebiasaan (adat). 


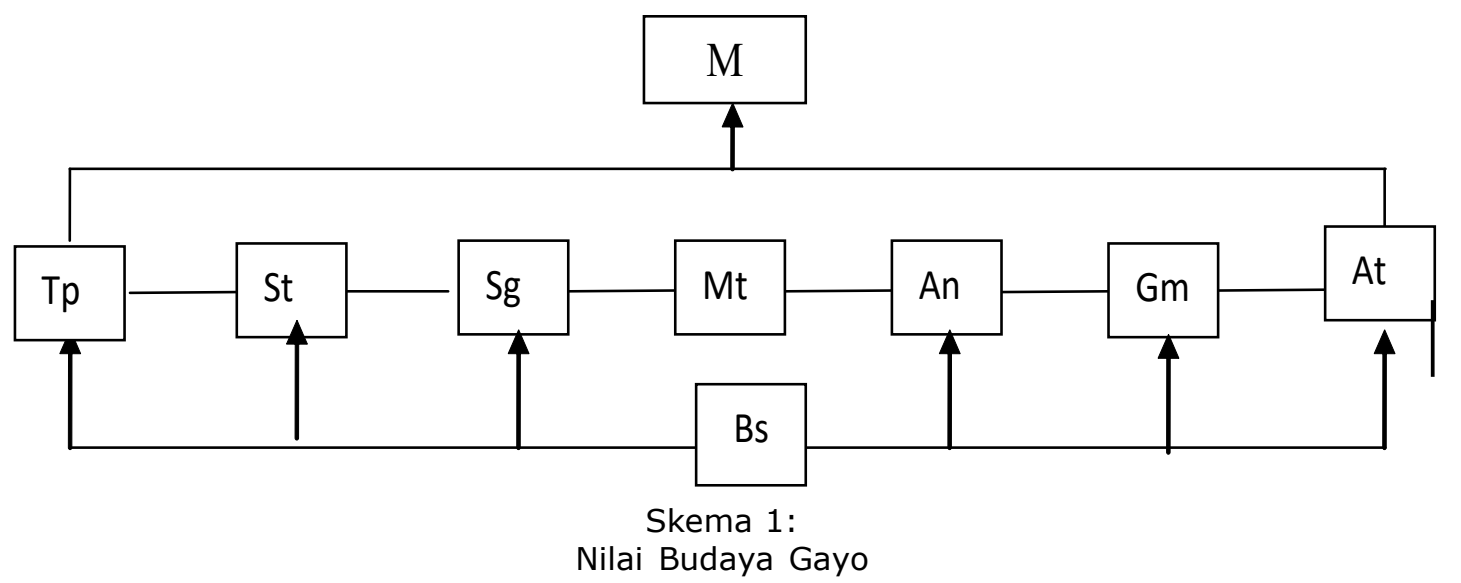

Keterangan:

M Mukemel

St Setie

Mt Mutentu

Gm Genap-Mupakat

Bs Bersikekemelen

Tp Tertip

Sg Semayang-Gemasih

An Amanah

At Alang-Tulung

\section{Tertib}

Kata ini berasal dari bahasa Arab, tartib, artinya teratur atau berurutan. Dalam masyarakat Gayo, tertib berkenaan dengan sikap hati-hati sehingga tindakan dan perlakukan dilakukan dengan memperhatikan konteks. Ungkapan bahasa Gayo menyatakan, tertib bermejelis, umet bermulie (artinya, keteraturan dalam kehidupan bersama merupakan prasyarat mewujudkan kemuliaan umat). Ungkapan ini menegaskan bahwa dalam sebuah komunitas yang beragam; baik ditinjau dari keahlian, minat, kecenderungan, pengalaman dan perbedaan usia diperlukan tata tertib yang dapat mengatur terwujudnya harmonisasi sosial.

\section{Setie}

Setie artinya mempunyai komitmen, teguh pendirian atau setia. Kata ini merujuk pada sikap tidak mudah menyerah demi memperjuangkan kebenaran. Dalam ungkapan Gayo disebutkan, ike jema musara ate, ungke terasa gule. Ike geremusara ate, bawal terasa bangke, ungkapan ini bermakna kalau hati sudah sepakat sepahit apapun tantangan mudah diselesaikan, sebaliknya apabila komitmen hilang persoalan kecilpun dapat memicu masalah yang lebih besar. Tantangan yang berat sekalipun akan lebih mudah dihadapi apabila komitmen telah terbentuk di antara para pihak.

\section{Semayang-gemasih}

Nilai budaya Gayo dalam konsep semayang- gemasih, artinya kasih sayang. Konsep ini berkaitan dengan prilaku terpuji dalam Islam, bahkan dua nama Allah yang baik (asmaul husna) dalam al-Qur'an adalah Maha Pengasih (alRahman) dan Maha Penyayang (al-Rahim). Dalam ungkapan bahasa Gayo, nilai semayang-gemasih ini tercantum dalam pribahasa; kasih enti lanih, sayang enti lelang, yang berkaitan dengan pentingnya kemampuan bertindak proporsional dalam berkasih sayang. Kasih sayang yang tidak diiringi pengetahuan dapat merusak, misalnya terlalu memanjakan anak atau memberi disertai sikap merendahkan, pamer atau penyesalan tidak akan mencapai taraf kesempurnaan kasih sayang (Ibrahim dan Pinan, 2010).

\section{Mutentu}

Nilai budaya mutentu sederhananya berarti rajin, pekerja keras, atau melaksanakan sesuatu sesuai aturan (rapi). Nilai ini memberi penekanan pada pembentukan sikap tidak terburu-buru atau ceroboh, tetapi berdasarkan perenungan dan perencanaan yang matang. Sifat ini merupakan indikator sangat penting dalam menilai karakter dan mempengaruhi kepercayaan orang lain. Seseorang yang terlanjur melakukan perbuatan yang mencederai kepercayaan yang diberikan kepadanya akan cacat status sosialnya dalam pergaulan. 


\section{Amanah}

Amanah berasal dari bahasa Arab, yang artinya terpercaya, jujur dan bertanggungjawab. Amanah berkaitan dengan kesesuaian antara ucapan dan perbuatan, keselarasan antara idealitas dan realitas. Sifat amanah dibuktikan oleh kemampuan seseorang menunaikan tugas atau kepercayaan yang diembankan secara bertanggungjawab, persesuaian ucapan dan perbuatan, menegakkan keadilan, ikhlas dan jujur, mengendalikan hawa nafsu (Ibrahim dan Pinan, 2010).

\section{Genap-Mupakat}

Genap-mupakat atau keramat-mupakat merupakan nilai budaya Gayo yang berkaitan dengan perwujudan harmoni sosial. Genap-mupakat merupakan pengejewantahan prinsip musyawarah untuk mencari solusi terbaik. Hurgronje (1992) menyatakan bahwa masyarakat Gayo mempunyai karakteristik sebagai orang republik yang bebas dan berani mengungkapkan pendapat tanpa terlalu terikat hierarki kekuasaan, sebagaimana berlaku dalam masyarakat feodal. Dalam perspektif masyarakat Gayo, penggunaan musyawarah merupakan bagian penting dalam memutuskan persoalan yang menyangkut hajat hidup publik.

\section{Alang-Tulung}

Nilai budaya Gayo lainnya adalah sikap tolongmenolong, sebagaimana tercermin dalam ungkapan alang-tolong berat-berbantu. Nilai ini menegaskan eksistensi manusia sebagai makhluk sosial, manusia memerlukan interaksi sosial yang memungkinan proses memberi dan menerima (give and take, bukan take and give sebagaimana sering disebut) sebagai perekat kohesi sosial.

\section{Bersikekemelen}

Untuk mengaktualisasikan sitim nilai-nilai budaya Gayo, Melalatoa (1982) mengungkapkan kemestian adanya nilai penggerak, bersikekemelen atau sikap kompetitif dalam mengamalkan ke tujuh nilai penunjang, dalam bahasa agama Islam dikenal dengan prinsip berlomba-lomba dalam kebaikan, fastabiqul khairat. Melalui nilai bersikekemelen, nilainilai lainnya akan lebih kokoh. Prinsip berlomban melakukan kebaikan mencakup upaya meningkatkan martabat kehidupan, misalnya dalam pengem- bangan ilmu pengetahuan, perbaikan taraf ekonomi dan dalam mengamalkan ajaran agama.

\section{Implementasi Teaching for Wisdom dalam pendidikan Karakter}

Kearifan lokal sebagai basis pendidikan karakter tidak memadai sebatas konsep, upaya menterjemahkan kearifan lokal yang telah melalui inventarisasi, seleksi, adaptasi, dan aplikasinya merupakan tantangan yang perlu mendapat perhatian. Inventarisasi kearifan lokal berkaitan dengan bagaimana pendidik bersama stakeholders pendidikan melakukan upaya identifikasi kearifan lokal. Kearifan lokal yang telah tersisihkan akibat modernisasi dan homogenisasi pembangunan berdampak semakin sedikitnya narasumber yang dapat dijadikan rujukan kearifan lokal, terlebih kebanyakan kearifan lokal diwariskan melalui tradisi lisan. Tahap berikutnya adalah perlu dilakukan pemilahan aspek-aspek kearifan lokal apa saja yang paling mendesak dan relevan dikembangkan. Pemilihan materi ini diperlukan karena sekolah dengan misi besarnya (mempersiapkan peserta didik mendapat pekerjaan, penyiapan warga negara yang baik, wadah aktualisasi diri, dan lain-lain) mempunyai keterbatasan waktu dan sumber daya.

Setelah memetakan kearifan lokal yang dipilih sebagai basis pendidikan karakter, tahap selanjutnya adalah bagaimana kearifan lokal tersebut diadaptasi sesuai realitas kekinian. Nilai mukemel dalam masyarakat Gayo misalnya, perlu reinterpretasi sehingga relevan dengan kondisi saat ini. Persyaratan ini diperlukan agar dalam mempelajari kearifan lokal pendidik dan peserta didik tidak terjebak pada penguasaan konsep, tetapi kehilangan makna atau dalam penjelasan Sternberg (2003) disebutnya know what, tetapi tidak know how. Dalam tahap aplikasinya, kearifan lokal harus menjadi sesuatu yang nyata ditunjukkan oleh kepala sekolah, guru, tenaga kependidikan, sehingga benar-benar menjadi kultur sekolah (schools culture). Apabila sinergi ini berhasil dilakukan, harapan terwujudnya sekolah yang lebih nyaman dan berhasil membangun karakter peserta didik tidak akan sebatas jargon dan menjadi bahan diskusi yang hangat dalam seminar, simposium, tetapi nihil dalam pelaksanaan. 


\section{Simpulan dan Saran}

\section{Simpulan}

Kompleksitas modernitas menuntut kreativitas berkesinambungan. Pendekatan homogen dalam menyelesaikan masalah terbukti tidak membawa hasil maksimal. Upaya menggali warisan kearifan lokal menjadi pilihan yang patut dipertimbangkan dalam pendidikan karakter yang saat ini digulirkan Kementerian Pendidikan dan Kebudayaan Nasional. Indonesia sebagai negara yang sangat bervariasi ditinjau dari keragaman budaya, bahasa, sudah seyogianya memperhatikan keunikan yang terdapat pada masing-masing komunitas. Tidak berarti bahwa identitas sebagai satu bangsa tidak perlu, tetapi bagaimana mencari titik kesimbangan dalam memposisikan kebhineka-an dalam ke-Ika-an. Untuk mewujudkan pendidikan yang lebih 'membumi' semestinya kearifan lokal diletakkan sebagai basis model dan implementasi pendidikan karakter di tanah air.

\section{Saran}

Komitmen pemerintah menjadikan pendidikan karakter sebagai salah satu prioritas kebijakan pendidikan nasional layak diapresiasi. Pengembangan konsep, model atau pendekatan untuk merealisasikan gagasan tersebut, perlu mendapat perhatian dari pihak-pihak yang terpanggil untuk turut serta berkontribusi dalam membenahi teori dan praktik (praksis) pendidikan nasional. Penanggung jawab pendidikan nasional, khususnya para pengambil kebijakan di Kementerian Pendidikan dan Kebudayaan baik pada tingkat nasional, regional dan daerah perlu memberi ruang lebih luas kepada berbagai komponen anak bangsa untuk mengembangkan pendekatan alternatif pendidikan karakter. Fasilitasi melalui pelatihan, pendampingan penelitian dan desiminasi model-model pendidikan karakter akan sangat menentukan masa depan praksis pendidikan karakter di Indonesia.

\section{Pustaka Acuan}

Abubakar, Mustafa. 2010. "Membangun Semangat Nasionalisme dengan Bingkai Kearifan Lokal Rakyat Aceh Tinjauan Ketahanan Pangan" [online]. Ttersedia: www.setneg.go.id. [12 April 2011]

Aspin, David N., Chapman, Judith D., Ed. 2007. Values Education and Lifelong Learning: Principles, Policies, and Programmes. Netherland: Springer.

Bowen, Jhon R. 1984. "The History and Structure of Gayo Society: Variation and Change in Highland of Aceh" Dissertasi. Chichago: University of Chicago.

Bowen, Jhon R. 1991. Sumatran Politics and Poetics: Gayo History, 1900-1989. New Haven: Yale University

Bowen, Jhon R. 1993. Muslims Through Discourse: Religion and Ritual in Gayo Society. New Jersey: Princeton University Press.

Bowen, Jhon R. 2003. Islam, Law, and Equality in Indonesia: An Anthropology of Public Reasoning. Cambridge: Cambridge University Press

Creasy. 2008. "What is Character Educaton?" dalam Educational Policy, Volume 3 Nomor 12, hal. 172180

Dendy Sugono., Sugiyono., Meity Takdir Qudaratillah. 2008. Tesaurus Bahasa Indonesia. Jakarta: Pusat Bahasa Departemen Pendidikan Nasional.

Dimenson, Sara, Ed. 2009. Character Is Key: How to Unlock the Best in Our Children and in Our Self. Ontario: John Wiley \& Sons Canada.

Eades, Domenyk. 2005. A Grammar of Gayo: A Language of Aceh, Sumatera. Canberra: The Australian National University

Eades, Domenyk., Hajek, John. 2006. "Gayo" dalam Journal of the International Phonetic Association. Volume 36 (1). Hal. 107-115

Gayatri, Irene Hiraswati, dkk., Ed. 2008. Runtuhnya Gampong di Aceh: Study Masyarakat Desa Yang Bergolak. Yogyakarta: Pustaka Pelajar 
Hurgronje, C. Snouck. 1996. Tanah Gayo dan Penduduknya. Terj. Budiman S. Jakarta: INIS Ibrahim, Mahmud. 2007. Mujahid Dataran Tinggi Gayo. Takengon: Maqamammahmuda.

Ibrahim, Mahmud., Pinan, A.R.Hakim Aman. 2002. Syari'at dan Adat Istiadat Jilid I. Takengon: Maqamammahmuda

Ibrahim, Mahmud., Pinan, A.R.Hakim Aman. 2003. Syari'at dan Adat Istiadat Jilid 3. Takengon: Maqamammahmuda

Ibrahim, Mahmud., Pinan, A.R.Hakim Aman. 2010. Syari'at dan Adat Istiadat Jilid 2. Cetakan ke-4. Takengon: Maqamammahmuda

Kupperman. 1990. Character. New York: Oxford University Press

Lang, Hellmut R., Evans, David N. 2006. Models, Strategies, and Methods for Effective Teaching. Boston: Pearson Education. Inc.

Lickona, Thomas. 1991.. Educaton for Character: How Our School Can Teach Respect and Responsibilty. New York: Bantam Books

Melalatoa, M. Junus. 1982. Kebudayaan Gayo. Jakarta: Balai Pustaka

Nucci, Larry P., Narvaez, Darcia, Ed. 2008. Handbook of Moral and Character Education. Washington: American Psychological Associaton

Peterson, Christoper., Seligman, Martin E. P. 2004. Character Strenghts and Virtues: A Handbook and Classification. New York: Oxford University Press.

Rasyidin, Al., Siregar, Parluhutan., Batubara, Khuzaimah. 2009. "Penyerapan Nilai-Nilai Budaya Lokal dalam Kehidupan Beragama di Medan: Studi Tentang Budaya Lokal di Medan" dalam Afif dan Bahri, Saeful. Harmonisasi Agama dan Budaya di Indonesia (2). Jakarta: Balitbang Kemenag.

Reagen, Timothy. 2005. Non-Western Educational Traditions: Indigenous Approaches to Educational Thought and Practice. Third Edition. New Jersey: Lawrence Erlbaum.

Rosenthal, Franz. 2003. Knowledge Thriumphant: The Concept of Knowledge in Medieval Islam. New York: Routledge

Said, Muhammad. 1985. Aceh Sepanjang Abad. Medan: Penerbit Waspada

Sternberg, Robert J. 2009. "A Balance Theory of Wisdom" dalam Kaufman, James C., Grigorenko, Elena L. Ed., The Essential Sternberg: Essay on Intelligence, Psychology and Education. New York: Springer Publishing Company.

Sternberg, Robert J. 2003. Wisdom, Intelligence, and Creativity Synteshized. New York: Oxford University Press

Sternberg, Robert J. 2004. "Wisdom and Giftedness" dalam Shavinina, Larisa V., Ferrari, Michel., Ed., Beyond Knowledge: Extra Cognitive Aspects of Developing High Ability. New Jersey: LawrenceErlbaum.

Sternberg, Robert J. 2005. "Foolishness" dalam Sternberg, Robert J., Jordan, Jennifer. Ed. (2005). A Handbook of Wisdom: Psychological Perspective. Cambridge: Cambridge University Press.

Sternberg, Robert J. 2010. "Academic Intelligence is Not Enough! WICS: An Expanded Model for Effective Practice in School and Later Life" dalam Preiss, David D., Sternberg, Robert J., Ed., Innovations in Educational Psychology: Perspective on Learning, Teaching and Human Development. New York: Springer Publishing Company.

Sternberg, Robert J., Grigorenko, Andrey. 2004. Culture and Competence: Contexts of Life Success. Washington: American Psychological Association

Sternberg, Robert J., Jarvin, Linda., Reznitskaya, Alina. 2008. "Teaching for Wisdom Through History: Infusing Wise Thinking Skills in School Curriculum" dalam Ferrari, Michel., Potworowski, Georges., Ed., Teaching for Wisdom: Cross-Cultural Perspectives on Fostering Wisdom. Netherland: Springer

Sternberg, Robert J., Jordan, Jennifer. Ed. 2005. A Handbook of Wisdom: Psychological Perspective. Cambridge: Cambridge University Press. 
Sternberg, Robert J., Kaufman, Scott Barry., Ed. 2011. The Cambridge Handbook of Intelligence. Cambridge: Cambridge University Press.

Syukri. 2007. Sarakopat: Sistem Pemerintahan Tanah Gayo dan Relevansinya terhadap Pelaksanaan Otonomi Daerah. Bandung: Citapustaka Media 